\title{
Approximation as a Semantic Process of Occasional Modification of the Meaning
}

\author{
Marine Yaghubyan \\ Yerevan State University
}

\begin{abstract}
Approximation is a semantic process when occasional modification of meaning, i.e. partial actualization of a linguistic unit is carried out. This process takes place when one of the elements of a situation, an object, an action or a quality mentioned is questionable as to its correspondence to the referent. As a result of this the latter is denoted approximately, not precisely by the speaker or writer.

The paper examines different types of approximators (approximators proper, minimizers, compromizers) in order to assess the semantic relations between certain adverbs that function as approximators. The analysis shows that the adverbs used as approximators are not identical and cannot be called absolute synonyms. Vocabulary acquisition is not an easy job for foreign language learners. It becomes even more challenging when it comes to the learning of synonyms. Though synonymous approximators share some of the meanings, they are not interchangeable in all contexts. Furthermore, the analysis comes to prove that the occurrence of approximators across various registers differs.
\end{abstract}

Key words: approximation, modification of meaning, minimizer, compromizer, absolute synonym, near synonym, hedge.

\section{Introduction}

According to traditional grammar, the word is the basic unit of syntax and semantics. General linguistics has always been concerned with the problem of relations between words and things they denote, i.e. referents. The relation 
which exists between words and their referents, i.e. things, events, actions and qualities is known as correlation (reference), but correlation cannot be always exact and precise. Absolute correspondence is something that can hardly ever be found as the boundaries between objects in extra linguistic reality are sometimes difficult to define (Butterfield 2008).

In the process of communication some lexical units are often indefinite, not exact or precise in meaning. Hence, a word used in the flow of speech may only partly characterize the objects and things. The linguistic means which express approximation, i.e. approximators, can be realized on different levels: morphological, syntactic, phraseological and phonetic (Quirk et al. 1985:597-98).

Approximation is a semantic process when occasional modification of meaning, i.e. partial actualization of a linguistic unit is carried out. This phenomenon takes place when one of the elements of a situation, an object, an action or a quality mentioned is questionable as to its correspondence to the referent. As a result of this, the latter is denoted approximately, not precisely by the speaker or writer.

The majority of linguistic units having the meaning of "approximation" refer to adverbs: "approximately", "somewhat" and so on. Here also belong such adverbial collocations as "in a way", "more or less". Approximation includes also a number of adverbial modifiers of degree, i. e. "almost", "hardly", "nearly" "scarcely", "barely", and the adverbial collocations "kind of", "sort of'(Carter 2006).

According to R. Quirk and S. Greenbaum, approximators belong to the group of down toners which have a lowering effect on the force of the word. They are divided into the following types:

- approximators proper: "almost", "nearly" which imply a denial of the truth value of what is denoted by the verb;

- minimizers: "hardly", "scarcely", "barely" which partially deny the truth value of what is said;

- compromizers: "kind of", "sort of", which reduce the force of the verb and the noun;

- diminishers: "somewhat”, "somehow” (Quirk et al. 1985:597-98). 
Defining approximators as degree adverbs, G. Leech points out that degree can be applied only to gradable words whose meaning can be thought of in terms of a scale. Therefore, he distinguishes two kinds of gradable words:

- scale words, which indicate a relative position on a scale (almost, nearly);

- limit words, which indicate the end point of a scale (completely, absolutely) (Leech 1991:20).

Let us examine the use of different types of approximators in speech in order to identify the semantic relationship between synonymous words expressing imprecise meaning.

\section{Approximators proper: "almost", "nearly"}

Defining adverbs as words denoting circumstances or characteristics modifying actions, a state or a quality, we can single out a group of degree adverbs which may intensify or weaken a quality or characteristics, like "nearly", "almost".

These adverbs are considered to be synonymous. It is well-known that synonymy is considered one of the "sense relations", or in other words, "the meaning relations that hold within the vocabulary of a language between words themselves" (Harris 1973:6). H. Jackson claims that "synonymy deals with sameness of meaning, more than one word having the same meaning, or alternatively the same meaning being expressed by more than one word"(Jackson 1988:64). L. Linsky states that "two linguistic expressions are synonymous if and only if they have the same meaning" (Linsky1952:111). R. Harris focuses on the relationship between form and meaning and suggests that "there may be cases in which a difference of form between two expressions is not accompanied by a difference of meaning: in such cases we may speak of synonymous expressions" (Harris 1973:6).

The adverb "almost" that means "nearly" is used to modify a verb. It is usually placed before notional verb, but after the auxiliary verb or link verb. 
E.g. 1. Why, I know things, good and bad, big and little, about men and women and life that sometimes I almost doubt myself that they're true. But I know them.

(London 1916:11)

2. He rode through what was almost a village, save that there were neither shops nor hotels.

(London 1916:9)

From these examples it becomes clear that the meaning of the approximator "almost" in both cases is the same-"not quite", while the position of the adverbs is different.

"Almost" is used with adjectives, time expressions and periods of time or quantities of things but before pronouns like any, anybody, anything, etc.

E.g. 1. "I don't know what to think," replied poor Giles. "I don't think it is the boy; indeed, I'm almost certain that it isn't."

(Dickens 2003:55)

2. I'll eat almost anything you give, Aunt Minnie.

(Escott 1995:12)

3. Twenty - almost twenty-one. I asked him this afternoon. I didn't think he was that young."

(London 1909:63)

In these examples the approximators express the same meaning with a slight difference. Thus in (1) the meaning is "very nearly about", in (2) - "all just about", in (3) - "most near". These examples show that it is not completely the case but is nearly the case,

There is one more interesting point to make. "Almost" is used with like to indicate that two things are very similar. In the following example comparison is used to describe resemblance. 
E.g. The dam was a bright sorrel - almost like a fresh-minted twenty-dollar piece - and I did so ant a pair out of her, of the same color, for my own trap.

(London 1916:87)

We can state that the use of approximators may vary in British English and American English. In British English "very" and "so" can be used before "nearly". In the following example the adverb "so" modifies the approximator "nearly" and intensifies the meaning of proximity.

E.g. On the right is the garden of Madame Olivier's villa, on the left the garden of another villa - and from that garden, mark you, the tree fell - so nearly on us.

(Christie 1927:95)

Our analysis shows that "almost" is used much more frequently than "nearly" and is therefore likely to be less specialized than the latter; "nearly" is used to indicate that something is not quite the case, or not completely the case. They are both used to express ideas connected with progress, measurement or counting.

\section{Minimizers: "hardly", "scarcely", "barely"}

Now let us analyze the minimizers "hardly", "scarcely" and "barely". Though these minimizers mostly appear as a subgroup of adverbs of degree, it is important to point out that some grammarians place them in a separate group (Chalker 1984:201; Sinclair 1990:285). According to S. Chalker, the following adverbs fall into the group of intensifiers (Chalker1984:201). J. Sinclair also creates a separate category and labels these adverbs "broad negatives" (Sinclair 1990:214).

The most convenient classification is provided by R. Quirk et al who place these adverbs into the group of intensifiers, specifically minimizers. The meanings of "hardly" and "scarcely" share are "almost not" and they are all used to emphasize that something happened immediately before something else. However, only "hardly" and "scarcely" are used to indicate that something is not likely or reasonable, in other words they mean "definitely not". On the other 
hand, it is just "barely" that is used to emphasize how small a number or amount is. Unlike "scarcely" and "barely", "hardly" is associated with difficulty of doing something. What is more, "hardly" is employed in special context, when something impossible is suggested, to mean "no" (Quirk et al. 1985:589-90).

Let us examine the case where "hardly" can mean "to almost no degree; almost not; probably or almost surely not; with severity, harshly; with great difficulty; painfully". In the following example the doer notes that he did some action with great difficulty. He is trying to convince her interlocutor to agree with him.

E.g. I could hardly prevent myself from there and then kneeling down at his feet and telling him what I had done.

(Doyle 2007:52)

Like "hardly", "scarcely" can't be used in negative sentences. "Scarcely" can mean "almost not" and can replace "hardly". But "scarcely" is chiefly used to mean "not quite". In the following example the author implies that Nancy was able to perform an action "without looking" at her partner.

E.g. Nancy, scarcely looking at the boy, threw him a handkerchief to tie round his throat; Sikes gave him a large rough cape to button over his shoulders.

(Dickens 2003:85)

These adverbs mostly function as premodifiers and they precede the words they modify or refer to (Quirk et al.1985:441; Chalker 1984:201). The adverb "barely" can mean "not more than / only just".

E.g. He backed the car out of the garage one morning and could barely push the brakes.

(Album 2003:8)

The adverb "barely" is used to emphasize that something happens immediately after a previous action and we can see that the word "barely" has the meaning "hardly", "not enough" and can be easily substituted by "scarcely". 
However, viewed from the point of the degree of approximation, "barely" stands closest to the category of completeness. Furthermore, we employ "barely" when we want to say that something happened but it almost did not. In other words," barely" indicates that something almost does not happen or exist, or is almost not possible. Evidently, it is connected with describing a sequence of events. It is applied when we want to emphasize that something happened only a very short time before something else. Furthermore, all the adverbs are employed in language to "emphasize that something happens immediately after a previous action” (LDCE 2003:105). They are all connected with sequence of events.

These two meanings are shared by all the three adverbs. Nevertheless, there are some additional meanings which are associated only with one or two of these adverbs. The adverbs "hardly" and "scarcely" can indicate that "something is not at all reasonable or likely" (OALDCE 1998:1303). They both mean "certainly, definitely not". Evidently, the adverb "barely" is not very common in this sense.

Both "barely" and "hardly express that "it is difficult to do something" (OALDCE 1998:680) and that something happens but "only with great difficulty or effort" (LDCE 2003:105).

E.g. She was very old and barely able to walk. (LDCE 2003:105)

E.g. I can hardly keep my eyes open.

(OALDCE 1998:680)

Bäcklund points out that all the three adverbs have pessimistic colouring, however, "hardly" implies a more pessimistic frame of mind than "barely". In other words, the negative aspect of "barely" is much weaker than that of "hardly". It is also claimed that "hardly" is used in more emotional contexts, to a great extent expressing failure to reach a desirable standard, whereas "scarcely" seems to occur more often in neutral collocations" (Bäcklund 1973:37-40).

The adverbs also differ in terms of words they occur with. While "barely" most often precedes verbs, adjectives, and numerals, "hardly" is followed mainly 
by verbs, adjectives, and adverbs. "Scarcely" can be found mostly with verbs, adjectives, and nouns. Furthermore, it is obvious that pronouns co-occur almost exclusively with "hardly", and numerals with "barely". "Hardly" often occurs with the following words: be, surprising, ever, believe, and knew. Analyzing the collocations of the adverbs unlike "barely", both "hardly" and "scarcely" often occur with ever (hardly ever, scarcely ever). "Barely" forms frequent expressions with adjectives related to senses: audible, perceptible, visible, discernible, and the word able. "Scarcely" is followed mainly by be, have, and surprising. What is more, the word alive is used only with "barely", whereas fair is found only after "hardly". Ever, likely and surprising form very frequent expressions with "hardly", however, they are never used after "barely" (Bolinger 1972:59; Borst 1967:22).

Our analysis shows that the adverbs "barely", "hardly", and "scarcely" are equal in some of their meanings. However, it is important to point out that they are not coincident in all contexts. Moreover, each of the adverbs forms different collocations and is part of different grammatical constructions. In this respect, "hardly" and "scarcely" seem to be more similar.

\section{Compromizers: "kind of", "sort of"}

The interpersonal and the semantic dimension of hedges have sometimes been used in literature as a basis for the creation of typologies. The category of hedges contains expressions such as "sort of", "kind of", "somewhat", "a bit". The speakers can avoid giving emphasis to their role in interaction by using approximators, thus they could be characterized as markers of denotational vagueness. They help to reduce the force of what speakers are saying. Approximators are hedges that affect the propositional content but not the speaker commitment. They are used to make some adaptation to some extent of the prepositional meaning so as to make the interpretation more close to the fact or used to give a range or limit the meaning to a certain scope (Lakoff 1972, Skelton 1988).

Approximators such as "sort of", "kind of", "basically", as well as "about", "around" and "approximately" can have the effect of conveying uncertainty, an 
unwillingness or inability to assert precise propositions or provide sufficient information. Approximators are hedges like "sort of" which semantically indicate some markedness with regard to group membership. "Sort of" and "kind of" make us appear less than sure of our ideas. If one is less than sure, it can be called an approximation (Aijmer 2002).

The adverbial collocations "kind of", "sort of" expressing approximation can be preceded only by an indefinite article or zero article.

E.g. 1. It was a sort of bed, small and soft.

(Doyle 2007:101)

2. That was sort of a joke.

(Escott 1995:77)

If there is a definite article or any other pre-modifier before "kind of", "sort of", that means it is not the approximation we deal with but noun-phrases the semantic meaning of which is "type of something".

E.g. Now you know the sort of perfectly splendid modern young lady I am.

(Shaw 1957:187)

"Kind of", "sort of" are not preceded by an article when they are used with verbs. Considering the semantic meaning of "kind of", in the following example, we can say that the implication is as follows: we do not deny hating, but we seem to be deprecating what we are saying.

E.g. She kind of hated people like that.

(Shaw 1957:86)

In some cases the approximators "kind of" and "sort of" may occur in combination with modal verbs or between the part of the compound / verbal / modal predicate.

E.g. 1. I kind of might get hold of her father's money, but he wouldn't let me to.

(Shaw 1957:103) 
2. One might sort of describe it as a happy ending.

(Shaw 1957:107)

Our analysis shows that the use of the approximators "kind of" and "sort of" gives indeterminateness and vagueness to speech. The speaker appears less than sure of his/her ideas.

\section{Conclusion}

It appears from those definitions that the adverbs are so synonymous that they are sometimes defined in terms of each other. If they are so close in meaning, one may well wonder if there are any differences between them in the way they are used.

Comparing the definitions of these adverbs, we may say that these adverbs are equal in some of their meanings. However, it is also obvious that the adverbs slightly differ in some sense and are used in different communicative situations. Constructions vary both structurally and semantically. Therefore, we can conclude that approximations cannot be absolute synonyms.

\section{References:}

1. Aijmer, K. and Bengt, A. (eds) (1991) English Corpus Linguistics. Studies in Honour of Jan Svartvik. London: Longman.

2. Bäcklund, U. (1973) The Collocation of Adverbs of Degree in English. Uppsala: S. Academiae Ubsaliensis.

3. Butterfield, J. (2008) Damp Squid: The English Language Laid Bare. OUP.

4. Carter, R. and McCarthy, M. (2006) Cambridge Grammar of English. A Comprehensive Guide. Cambridge, UK: CUP.

5. Chalker, S. (1984) Current English Grammar. London: Macmillan.

6. Harris, R. (1973) Synonymy and Linguistic Analysis. Toronto: University of Toronto Press.

7. Jackson, H. (1988) Words and Their Meaning. London: Longman. 
8. Lakoff, G. (1972) Hedges: A Study in Meaning Criteria and the Logic of Fuzzy Concepts. Chicago: Linguistics Society.

9. Leech, G. (1991) An A-Z of English Grammar and Usage. England: Nelson.

10.Linsky, L. (ed.) (1952) Semantics and the Philosophy of Language. Urbana: University of Illinois Press.

11. Quirk, R.; Greenbaum, S.; Leech, G. and Svartvik, J. (1985) $A$ Comprehensive Grammar of the English Language. London: Longman.

12. Sinclair, J. (1990) Collins Cobuild English Grammar. London: Collins.

13. Skelton, J. (1988) Comments in Academic Articles. // Applied Linguistics in Society. London: Centre of International Language Teaching. / Ed. by P. Grunwell. British Association of Applied Linguistics.

14. (1982) Oxford University Learner's Dictionary of Current English. Oxford: OUP.

15. (1998) Oxford Advanced Learner's Dictionary of Current English. Oxford: OUP.

16. (2003) Longman Dictionary of Contemporary English. Harlow: Pearson Education.

\section{Sources of Data:}

1. Album, M. (2003) The Five People You Meet in Heaven. Hyperion.

2. Christie, Ag. (1927) The Big Four. London: Collins.

3. Dickens Ch. (2003) Oliver Twist. Philip Horne. Harmondsworth: Penguin.

4. Doyle, C. (2007) The Lost World. The Echo Library.

5. Doyle, C. (2008) The Return of Sherlock Holmes. Forgotten Books.

6. Escott, J. (1995) The Ghost of Genny Castle. Do Brasil: Longman.

7. London, J. (1909) Martin Eden. New York: The Macmillan Co.

8. London, J. (1916) The Little Lady of the Big House. New York: The Macmillan Co.

9. Shaw B. (1957) Pygmalion. Harmondsworth: Penguin books. 


\section{Ununulnpnıpjnı\& upunwhujunn}

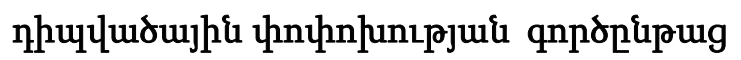

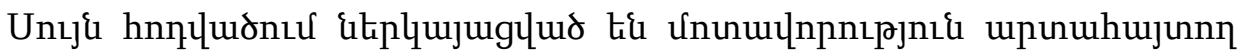

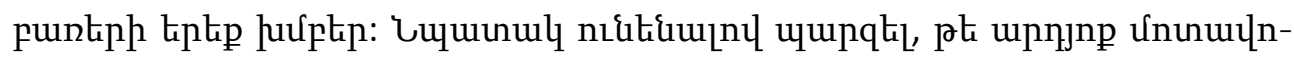

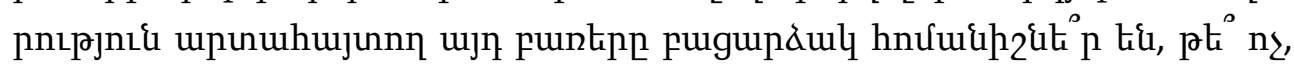

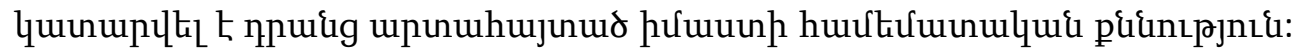

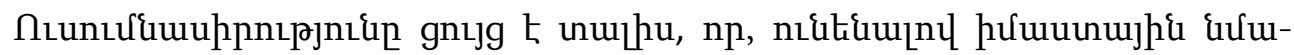

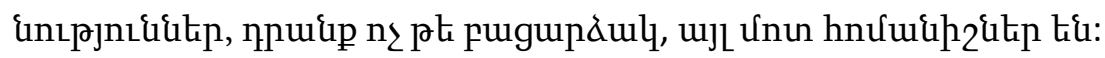

